\title{
Special Issue: Enhancing Sustainable Performance in Organizational and Inter-Institutional Systems
}

\author{
Graham Winch $^{1, *}$ and Carmine Bianchi ${ }^{2}$ * \\ 124 Church Street, Modbury, Devon PL21 0QR, UK \\ 2 CED4-System Dynamics Group, University of Palermo, Via Mazzini, 59-90100 Palermo, Italy \\ * Authors to whom correspondence should be addressed; \\ E-Mails: graham.winch@plymouth.ac.uk (G.W.); bianchi.carmine@gmail.com (C.B.); \\ Tel.: +44-1548-830816 (G.W.); +39-338-9244463 (C.B.).
}

Received: 6 May 2013 / Accepted: 6 May 2013 / Published: 13 May 2013

Sustainability is not just for Christmas... it's for life. Sustainable solutions, whether sought in terms of business strategies, social policies, or the exploitation of natural resources have to serve organizations and communities in the long term, sometimes very long term, as well as the short term. Static analysis is unlikely to be able to evaluate candidate solutions fully, and is more likely to focus on the short-term future to the detriment of the longer-term. Sustainable solutions are more likely to be developed from studies based on deep analysis using systems approaches, and from system dynamics (SD) approaches in particular.

Further, isolated approaches for enhancing sustainability management in real organizational and inter-organizational contexts run the risk of leading to "unsustainable" implementations if such models do not properly fit with the currently used performance management systems. So, what kind of support can dynamic modeling give to wider (strategic) performance management systems? What "missing links" (or information gaps) in how traditional performance management approaches support decision makers to frame sustainability issues can be filled by dynamics system modeling?

This special issue plans to publish new and imaginative insights into sustainability and the processes in seeking and evaluating strategies for sustainability using systems approaches. The issue welcomes, but is not limited to, articles using system dynamics either as the prime approach or in conjunction with other systems and management approaches.

(C) 2013 by the authors; licensee MDPI, Basel, Switzerland. This article is an open access article distributed under the terms and conditions of the Creative Commons Attribution license (http://creativecommons.org/licenses/by/3.0/). 